\title{
Importance of Ankle/Brachial Pressure Index in Saudi Patients with Coronary Artery Disease
}

\author{
Abdullah M. Alshehri ${ }^{1}$, Mohamed Elsharawy ${ }^{2 *}$ \\ ${ }^{1}$ Departments of Internal Medicine (Cardiology Division), University of Dammam, Dammam, KSA \\ ${ }^{2}$ General Surgery (Vascular Division), University of Dammam, Dammam, KSA \\ Email: "elsharawya@yahoo.co.uk
}

Received May 10, 2013; revised June 10, 2013; accepted June 18, 2013

Copyright (C) 2013 Abdullah M. Alshehri, Mohamed Elsharawy. This is an open access article distributed under the Creative Commons Attribution License, which permits unrestricted use, distribution, and reproduction in any medium, provided the original work is properly cited.

\begin{abstract}
Background: The ankle/brachial pressure index (ABPI) has been shown to be a good marker of systemic atherosclerosis and a powerful predictor of cardiovascular morbidity and mortality. The objective of this study was to determine the importance of measuring ABPI in Saudi patients with coronary artery disease (CAD). METHODS: This is a hospital based cross-sectional study which was conducted on all Saudi patients who underwent coronary angiography without symptoms of peripheral arterial disease at King Fahd Hospital of the University, Al-Khobar Saudi Arabia. All patients underwent measurement of their ABPI. The study was carried out between December 2010 and November 2011. RESULTS: During the study period, two hundred and five patients were included. Fifty-nine (28.8\%) patients were Group II $(\mathrm{ABPI} \leq 0.90)$ and the rest was Group I $(\mathrm{ABPI}>0.90)$. Significant correlation was also found between low ABPI and the extent of CAD (mean number of arteries involved in Group I was $1.78 \pm 0.83$ compared to $2.10 \pm 0.736$ in Group II $\mathrm{p}=0.011$ ). Nevertheless, the correlation between low ABPI, and the severity of presentation of CAD were also significant (Incidence of myocardial infarction with congestive heart failure was $0.5 \%$ in Group I compared to $12 \%$ in Group II $p<0.001)$. CONCLUSION: The ABPI is an important prognostic indicator for Saudi patients with CAD.
\end{abstract}

Keywords: Coronary Artery Disease; Ankle Brachial Pressure Index; Atherosclerosis

\section{Introduction}

Atherosclerotic diseases are the leading causes of death throughout the world and are estimated to account for $24 \%$ of all mortality worldwide in the year $2000[1,2]$. Atherosclerosis is a systemic disease and can affect different territories at the same time [3-6]. There was more than one arterial territory affected at the same time in $12 \%$ [1] - 40\% [7]. Several epidemiological studies have shown positive association between coronary artery disease (CAD) and peripheral arterial disease (PAD) $[4,8,9]$. The ankle/brachial pressure index (ABPI), used to diagnose PAD, has been shown to be a good marker of systemic atherosclerosis and a powerful predictor of cardiovascular morbidity and mortality [10]. The objective of this study was to determine the importance of measuring ABPI in Saudi patients with CAD.

\section{Patients and Methods}

This is a hospital based cross-sectional study on consecu-

${ }^{*}$ Corresponding author. tive series of patients underwent coronary angiography without symptoms of PAD at King Fahd Hospital of the University, Al-Khobar Saudi Arabia. "ABPI" has been measured for all patients. The study was carried out between December 2010 and November 2011.

Risk factors for atherosclerosis were stratified for all patients including: diabetes mellitus, smoking, dyslipidemia, hypertension and obesity measured by body mass index (BMI). Information on age and gender was also recorded.

Hypertension was defined as mean systolic blood pressure of $\geq 140 \mathrm{mmHg}$, mean diastolic blood pressure of $\geq 90 \mathrm{mmHg}$, physician diagnosis, or medication use. Average blood pressure was composed of up to four readings on two separate occasions. Dyslipidemia was defined as triglyceride level $\geq 150 \mathrm{mg} / \mathrm{dl}$ and/or HDL level $\leq 40 \mathrm{mg} / \mathrm{dl}$ in males or $\leq 50 \mathrm{mg} / \mathrm{dl}$ in females and/or LDL-C level $\geq 160 \mathrm{mg} / \mathrm{dl}$ and/or physician diagnosis or medication use. Diabetes was defined as self-reported physician diagnosis, use of antihyperglycemic agents, fasting glucose of $\geq 126 \mathrm{mg} / \mathrm{dl}$ in 3 separate occasions, 2 
hours post $75 \mathrm{gm}$ oral glucose tolerance test of $\geq 200$ $\mathrm{mg} / \mathrm{dl}$ in 3 separate occasions, random blood glucose $\geq 200 \mathrm{mg} / \mathrm{dl}$ in the presence of classical symptoms of hyperglycemia or hemoglobine $\mathrm{A} 1 \mathrm{C}>6.5 \%$.

\subsection{Coronary Angiography}

All patients underwent selective coronary angiography using the standard technique. Lesion severity assessed visually if more than $70 \%$ or less than $40 \%$ but for lesions between 40\% - 70\% Computer-Assisted Quantitative Angiography (QCA) used to calculate the severity of the lesion. Lesion considered being significant if the luminal stenosis exceeds $50 \%$ in any epicardial vessel. The extent of CAD was reported as one, two or three vessel disease and if there is left main artery involvement. The presentation of CAD was graded as: stable angina, Non ST elevation acute coronary syndrome (NSTEMI), STelevation acute coronary syndrome (STEMI) and/or congestive heart failure.

A comprehensive medical history was obtained from all patients, full physical examination was performed with special attention to palpating pulses in both lower extremities. Any patient had history of claudication, rest pain, ulcer, ischemic ulcer or gangrene was excluded from the study. Measuring of ABPI was obtained from each extremity using a Multi Doppler II Advanced Bidirectional Doppler (Huntleigh, UK). The higher measured values of the arm and ankle pressures (dorsalis pedis or posterior tibial) were used to calculate ABPI. Patients were considered to have PAD if the ABPI was $<0.9$. The blood pressure was measured by one trained nurse and the ABPI by consultant or senior registrar in vascular surgery.

Patients were divided into 2 groups based on the ABPI results. Those with $\mathrm{ABI} \geq 0.9$ were assigned as Group I and those $<0.9$ as Group II.

\subsection{Statistical Analysis}

Comparison between prevalence of risk factors in both Groups I \& II was done. Data of the 2 groups were summarized either as the mean \pm standard deviation (SD) or as percentage of the risk factors. Differences between the groups were tested for statistical significance using t-test, chi-square test or Fisher's exact test as appropriate. Significance was set at $\mathrm{p}<0.05$ and $0.05-0.1$ was considered as statistical trend for all comparisons. Statistical analyses were performed using SPSS 15 software (Chicago, USA).

\section{Results}

During the study period, two hundred and five patients were included. The mean age $( \pm \mathrm{SD})$ was $54.7 \pm 9.73$ years (range 29 - 81) with high incidence of dyslipidemia
(86\%) Table 1. One hundred forty six (71.2\%) of our patients were classified as group I and Fifty nine (28.8\%) patients as Group II. Group II was significantly older than Group I (53.27 \pm 9.06 in Group I compared to 58.25 \pm 10.52 in Group II $p=0.001$ ). There was also signifycant difference between both groups in the incidence of diabetes mellitus (74 (51\%) in Group I compared to 42 $(71 \%)$ in Group II $p=0.012)$ and hypertension $(72(49 \%)$ in Group I compared to $44(75 \%)$ in Group II $p=0.001)$. There were no significant differences between both groups as regards gender distribution, dyslipidemia, smoking, family history and BMI (Table 2).

Significant correlation was also found between low ABPI and the extent of CAD (mean number of arteries involved in Group I was $1.78 \pm 0.83$ compared to $2.10 \pm$ 0.736 in Group II $p=0.011$ Table 3). Nevertheless, the correlation between low ABPI, and the severity of presentation of CAD was also significant (Incidence of Myocardial infarction with congestive heart failure was $0.5 \%$ in group I compared to $12 \%$ in Group II $p<0.001$ ) (Table 4).

\section{Discussion}

Peripheral arterial disease is a common manifestation of atherosclerosis [11]. It is associated with increased risk for cardiovascular events due to coexistence of CAD and cerebrovascular disease, such events being more frequent

Table 1. Patients characteristic.

\begin{tabular}{lc}
\hline \multicolumn{1}{c}{ Characteristic } & No \\
\hline Age $($ mean \pm SD) & $54.7 \pm 9.73$ \\
Sex: Male/Female & $167 / 38$ \\
Diabetes & $116(56 \%)$ \\
Smoking & $87(42 \%)$ \\
Hypertension & $116(56 \%)$ \\
Dyslipidemia & $176(86 \%)$ \\
Family history of cardiovascular disease & $20(10 \%)$ \\
BMI (mean \pm SD) & $28.6 \pm 5.11$ \\
\hline
\end{tabular}

Table 2. Risk factors for atherosclerosis.

\begin{tabular}{lccc}
\hline & $\begin{array}{c}\text { Group I } \\
\text { (No. 146) }\end{array}$ & $\begin{array}{c}\text { Group II } \\
(\text { No. 59) }\end{array}$ & p value \\
\hline Age (mean \pm SD) & $53.27 \pm 9.06$ & $58.25 \pm 10.52$ & 0.001 \\
Sex (male/female) & $123 / 23$ & $44 / 15$ & 0.11 \\
Diabetes mellitus & $74(51 \%)$ & $42(71 \%)$ & 0.012 \\
Hypertension & $72(49 \%)$ & $44(75 \%)$ & 0.001 \\
Dyslipidemia & $126(86 \%)$ & $50(85 \%)$ & 0.77 \\
Smoking & $62(43 \%)$ & $25(42 \%)$ & 0.99 \\
Family history & $16(11 \%)$ & $4(7 \%)$ & 0.36 \\
BMI (mean \pm SD) & $29.3 \pm 5.6$ & $28.4 \pm 4.9$ & 0.26 \\
\hline
\end{tabular}


Table 3. Extent of coronary artery disease.

\begin{tabular}{lccc}
\hline & $\begin{array}{c}\text { Group I } \\
\text { (No. 146) }\end{array}$ & $\begin{array}{c}\text { Group II } \\
\text { (No. 59) }\end{array}$ & p value \\
\hline Number of single vessel (\%) & $70(48 \%)$ & $11(19 \%)$ & $<0.0001$ \\
Number of two vessels (\%) & $38(26 \%)$ & $26(44 \%)$ & 0.013 \\
$\begin{array}{l}\text { Number of three vessels (\%) } \\
\text { Number of vessels }\end{array}$ & $38(26 \%)$ & $22(37 \%)$ & 0.090 \\
(mean \pm SD) & $1.78 \pm 0.83$ & $2.10 \pm 0.736$ & 0.011 \\
LM involvement (\%) & $6(4 \%)$ & $4(7 \%)$ & 0.474 \\
\hline
\end{tabular}

Table 4. Presentation of coronary artery disease.

\begin{tabular}{lccc}
\hline & $\begin{array}{c}\text { Group I } \\
\text { (No. 146) }\end{array}$ & $\begin{array}{l}\text { Group II } \\
\text { (No. 59) }\end{array}$ & p value \\
\hline $\begin{array}{l}\text { Stable angina } \\
\text { NSTEMI acute coronary } \\
\text { syndrome }\end{array}$ & $55(27.5 \%)$ & $20(34 \%)$ & 0.30 \\
$\begin{array}{l}\text { STEMI acute coronary } \\
\text { syndrome }\end{array}$ & $51(35 \%)$ & $18(30 \%)$ & 0.33 \\
$\begin{array}{l}\text { Myocardial infarction with } \\
\text { congestive heart failure }\end{array}$ & $1(0.5 \%)$ & $7(12 \%)$ & $<0.11$ \\
\hline
\end{tabular}

than ischaemic limb events $[12,13]$. There is a $20 \%$ $60 \%$ increased risk for myocardial infarction (MI), a two to six-fold increased risk of cardiovascular death, and a $40 \%$ increased risk of stroke in patients with PAD [14]. These adverse consequences of PAD occur, in part, because many affected patients are not diagnosed, and those with known PAD often are undertreated. With the use of the ABPI, studies have shown that there is a significant increase in diagnosis of patients with PAD who have coexistent CAD [15-18]. The present study revealed that about $29 \%$ of our patients to have asymptomatic PAD.

The conventional risk factors for PAD and CAD including diabetes, hypertension, smoking and dyslipidemia were very common in our patients $(56 \%, 56 \%, 42 \%$ and $86 \%$ respectively) and this was concordant with data seen in previous studies [19-21]. The present study like others [22] has shown that different cardiovascular risk factors have variable influence on atherosclerosis in different territories. Diabetes was more frequent in PAD [7,22-27].

In population-based studies such as the Framingham Heart Study and Edinburgh Artery Study, the relative risk of developing PAD increases by 1.5 to 4 times in patients with diabetes [19-28]. These data is supporting remarkable impact of diabetes on the progression of the atherosclerotic process. Smoking was less evident in PAD in the present study. However, it was more apparent in other studies [7,22-27]. Whereas, the impact of dyslipidemia was less marked in PAD (present study and others $[7,23,24,29])$. In agreement with our results hypertension was more common in PAD [7,24]. There was agreement between current and previous study [30] that estimated that approximately $25 \%$ of patients over the age of 55 in a general medical practice have PAD.

Our Study demonstrated that among patients with documented CAD; $28 \%$ have asymptomatic PAD which is higher than that have been shown in other western studies $(21 \%$ - 22\%) [24,31]. This might indicate the higher prevalence of asymptomatic PAD in Saudi patients compared to other ethnic groups. In agreement with the Peripheral Arterial Disease in Interventional Patients Study (PIPS) [32] a significant correlation was found between low APBI and the extent of CAD (mean number of arteries involved). Furthermore, involvement of left main coronary was shown to be significantly higher in patients with PAD (present study and others [33]).

The presence of asymptomatic PAD confers on average a $30 \%$ risk of myocardial infarction, stroke, and vascular death over 5 years [34]. In our study, Patients with CAD and low ABPI had more incidence of myocardial infarction with congestive heart failure compared to those with ABPI $>1(12 \% 0.5 \% \mathrm{p}<0.001)$. This finding is very important since presence of PAD might be used in the risk stratification to indicate higher risk CAD patients who will need more aggressive intervention including percutaneous revascularization and coronary artery bypass surgery. In addition, early detection of PAD is fundamental to implement early risk Factor modification and disease management.

\section{Conclusion}

Our prospective study showed that PAD is highly prevalent among patients with angiographically documented CAD. Use of ABPI is a very valuable and easy diagnostic method to screen such patients for concomitant PAD. Low ABPI is associated with more diffuse CAD and linked to worse clinical outcome with higher incidence of myocardial infarction and congestive heart failure.

\section{REFERENCES}

[1] D. L. Bhatt, P. G. Steg, E. M. Ohman, A. T. Hirsch, Y. Ikeda, J. L. Mas, et al., "REACH Registry Investigators International Prevalence, Recognition, and Treatment of Cardiovascular Risk Factors in Outpatients with Atherothrombosis," JAMA, Vol. 295, No. 2, 2006, pp. 180-189. http://dx.doi.org/10.1001/jama.295.2.180

[2] P. G. Steg, D. L. Bhatt, P. W. Wilson, R. Sr. D’Agostino, E. M. Ohman, J. Röther, et al. (REACH Registry Investigators), "One-Year Cardiovascular Event Rates in Outpatients with Atherothrombosis," JAMA, Vol. 297, No. 11, 2007, pp. 1197-1206. http://dx.doi.org/10.1001/jama.297.11.1197

[3] D. L. Bhatt, "Diffuse Coronary Disease and Atherothrombosis: A Rationale for Long-Term Therapy to Prevent Recurrent Ischemic Events," Journal of Invasive Cardi- 
ology, Vol. 15, Suppl. B, 2003, pp. 3B-9B.

[4] P. Poredos and B. Jug, "The Prevalence of Peripheral Arterial Disease in High Risk Subjects and Coronary or Cerebrovascular Patients," Angiology, Vol. 58, No. 3, 2007, pp. 309-315. http://dx.doi.org/10.1177/0003319707302494

[5] K. I. Paraskevas, D. P. Mikhailidis and C. D. Liapis, "Internal Carotid Artery Occlusion: Association with Atherosclerotic Disease in Other Arterial Beds and Vascular Risk Factors," Angiology, Vol. 58, No. 3, 2007, pp. 329335. http://dx.doi.org/10.1177/0003319707301754

[6] G. Romano, E. Corrado, I. Muratori, G. Novo, G. Andolina, V. Cospite, et al., "Carotid and Peripheral Atherosclerosis in Patients Who Underwent Primary Percutaneous Coronary Intervention and Outcome Associated with Multifocal Atherosclerosis," International Journal of Angiology, Vol. 25, No. 4, 2006, pp. 389-394.

[7] M. A. Elsharawy, A. H. Alkhadra, M. F. Abdulmohsen and A. Bahnassy, "Impact of Atherosclerotic Risk Factors on the Extent of Arterial Occlusive Disease among Arab Patients. A Hospital Based Study," International Journal of Angiology, Vol. 28, No. 5, 2009, pp. 367-372.

[8] L. Missault, C. Krygier, G. Lukito and L. Mary-Rabine (OPERA Investigators Study Group), "Occurrence of Peripheral Arterial Disease in a Belgian Cohort of Patients with Cardiovascular History of Atherothrombosis," Acta Chirurgica Belgica, Vol. 107, No. 5, 2007, pp. 508-514.

[9] R. S. Dieter, J. Tomasson, T. Gudjonsson, R. L. Brown, M. Vitcenda, J. Einerson, et al., "Lower Extremity Peripheral Arterial Disease in Hospitalized Patients with Coronary Artery Disease," Vascular Medicine, Vol. 8, No. 4, 2003, pp. 233-236. http://dx.doi.org/10.1191/1358863x03vm506ra

[10] J. A. Carbayo, J. A. Divisón, J. Escribano, J. López-Abril, E. L. de Coca, L. M. Artigao, E. Martínez, C. Sanchis, J. Massó and L. Carrión (Grupo de Enfermedades Vasculares de Albacete (GEVA)), "Using Ankle-Brachial Index to Detect Peripheral Arterial Disease: Prevalence and Associated Risk Factors in a Random Population Sample," Nutrition, Metabolism \& Cardiovascular Diseases, Vol. 17, No. 1, 2007, pp. 41-49.

http://dx.doi.org/10.1016/j.numecd.2005.08.009

[11] J. J. Mourad, P. Cacoub, J. P. Collet, et al. (On Behalf of the ESC), "Study I. Screening of Unrecognized Peripheral Arterial Disease (PAD) Using Ankle-Brachial Index in High Cardiovascular Risk Patients Free from Symptomatic PAD," Journal of Vascular Surgery, Vol. 50, No. 3, 2009, pp. 572-580. http://dx.doi.org/10.1016/j.jvs.2009.04.055

[12] J. Ness and W. S. Aronow, "Prevalence of Coexistence of Coronary Artery Disease, Ischemic Stroke, and Peripheral Arterial Disease in Older Persons, Mean Age 80 Years, in an Academic Hospital-Based Geriatrics Practice," Journal of the American Geriatrics Society, Vol. 47, No. 10, 1999, pp. 1255-1256.

[13] J. Saw, D. L. Bhatt, D. J. Moliterno, et al., "The Influence of Peripheral Arterial Disease on Outcomes: A Pooled Analysis of Mortality in Eight Large Randomized Percutaneous Coronary Intervention Trials," Journal of the
American College of Cardiology, Vol. 48, No. 8, 2006, pp. 1567-1572. http://dx.doi.org/10.1016/j.jacc.2006.03.067

[14] P. Poredos and B. Jug, "The Prevalence of Peripheral Arterial Disease in High Risk Subjects and Coronary or Cerebrovascular Patients," Angiology, Vol. 58, No. 3, 2007, pp. 309-315.

http://dx.doi.org/10.1177/0003319707302494

[15] A. T. Hirsch, M. H. Criqui, D. Treat-Jacobson, et al., "Peripheral Arterial Disease Detection, Awareness, and Treatment in Primary Care," JAMA, Vol. 286, No. 11, 2001, pp. 1317-1324.

http://dx.doi.org/10.1001/jama.286.11.1317

[16] R. S. Dieter, J. Tomasson, T. Gudjonsson, et al., "Lower Extremity Peripheral Arterial Disease in Hospitalized Patients with Coronary Artery Disease," Vascular Medicine, Vol. 8, No. 4, 2003, pp. 233-236. http://dx.doi.org/10.1191/1358863x03vm506ra

[17] J. J. Mourad, P. Cacoub, J. P. Collet, et al. (On Behalf of the ESC), "Study I. Screening of Unrecognized Peripheral Arterial Disease (PAD) Using Ankle-Brachial Index in High Cardiovascular Risk Patients Free from Symptomatic PAD," Journal of Vascular Surgery, Vol. 50, No. 3, 2009, pp. 572-580. http://dx.doi.org/10.1016/j.jvs.2009.04.055

[18] P. Cacoub, J. P. Cambou, S. Kownator, et al., "Prevalence of Peripheral Arterial Disease in High-Risk Patients Using Ankle-Brachial Index in General Practice: A CrossSectional Study," International Journal of Clinical Practice, Vol. 63, No. 1, 2009, pp. 63-70.

http://dx.doi.org/10.1111/j.1742-1241.2008.01953.x

[19] W. B. Kannel and D. L. McGee, "Update on Some Epidemiologic Features of Intermittent Claudication: The Framingham Study," Journal of the American Geriatrics Society, Vol. 33, No. 1, 1985, pp. 13-18.

[20] J. A. Dormandy and R. B. Rutherford, "Management of Peripheral Arterial Disease. TASC Working Group. TransAtlantic Inter-Society Consensus (TASC)," Journal of Vascular Surgery, Vol. 31, No. 1, 2000, pp. S1-S296.

[21] C. Margeta, A. Giurgea, A. Hammer, et al., "Impact of International Guidelines on the Management of Cardiovascular Risk Factors in Diabetic Patients with Peripheral Arterial Disease," International Journal of Angiology, Vol. 28, No. 3, 2009, pp. 175-180.

[22] C. Guijarro, N. Mesa, J. Jiménez, E. Puras, C. Sánchez, F. J. Fernández-Sánchez, et al. (AIRVAG Study Researchers), "Similarities and Differences among Patients with Symptomatic Atherosclerosis Affecting Several Territories. The AIRVAG Cohort (Integral Attention to Global Vascular Risk)," Medicina Clínica, Vol. 127, No. 16, 2006, pp. 605-611. http://dx.doi.org/10.1157/13094417

[23] K. Wattanakit, A. R. Folsom, E. Selvin, B. D. Weatherley, J. S. Pankow, F. L. Brancati, et al., "Risk Factors for Peripheral Arterial Disease Incidence in Persons with Diabetes: The Atherosclerosis Risk in Communities (ARIC) Study," Atherosclerosis, Vol. 180, No. 2, 2005, pp. 389397.

http://dx.doi.org/10.1016/j.atherosclerosis.2004.11.024

[24] R. S. Dieter, J. Tomasson, T. Gudjonsson, R. L. Brown, M. Vitcenda, J. Einerson, et al., "Lower Extremity Pe- 
ripheral Arterial Disease in Hospitalized Patients with Coronary Artery Disease," Vascular Medicine, Vol. 8, No. 4, 2003, pp. 233-236. http://dx.doi.org/10.1191/1358863x03vm506ra

[25] J. D. Hooi, A. D. Kester, H. E. Stoffers, M. M. Overdijk, J. W. van Ree and J. A. Knottnerus, "Incidence of and Risk Factors for Asymptomatic Peripheral Arterial Occlusive Disease: A Longitudinal Study," American Journal of Epidemiology, Vol. 153, No. 7, 2001, pp. 666-672. http://dx.doi.org/10.1093/aje/153.7.666

[26] T. A. Elhadd, A. A. Al-Amoudi and A. S. Alzahrani, "Epidemiology, Clinical and Complications Profile of Diabetes in Saudi Arabia: A Review," Annals of Saudi Medicine, Vol. 27, No. 4, 2007, pp. 241-250. http://dx.doi.org/10.4103/0256-4947.51484

[27] S. O. Al-Sheikh, B. A. Aljabri, L. A. Al-Ansary, L. A. Al-Khayal, M. M. Al-Salman and M. A. Al-Omran, "Prevalence of and Risk Factors for Peripheral Arterial Disease in Saudi Arabia. A Pilot Cross-Sectional Study," Saudi Medical Journal, Vol. 28, No. 3, 2007, pp. 412414.

[28] F. G. Fowkes, E. Housley, R. A. Riemersma, et al., "Smoking, Lipids, Glucose Intolerance, and Blood Pressure as Risk Factors for Peripheral Atherosclerosis Compared with Ischemic Heart Disease in the Edinburgh Artery Study," American Journal of Epidemiology, Vol. 135, No. 4, 1992, pp. 331-340.

[29] R. E. Maser, S. K. Wolfson Jr., D. Ellis, E. A. Stein, A. L. Drash, D. J. Becker, et al., "Cardiovascular Disease and Arterial Calcification in Insulin-Dependent Diabetes Mellitus: Interrelations and Risk Factor Profiles. Pittsburgh Epidemiology of Diabetes Complications Study-V," Ar- teriosclerosis, Thrombosis, and Vascular Biology, Vol. 11, 1991, pp. 958-965.

http://dx.doi.org/10.1161/01.ATV.11.4.958

[30] J. J. Belch, E. J. Topol, G. Agnelli, et al., "Critical Issues in Peripheral Arterial Disease Detection and Management: A Call to Action," Archives of Internal Medicine, Vol. 163, No. 8, 2003, pp. 884-892. http://dx.doi.org/10.1001/archinte.163.8.884

[31] P. Poredos and B. Jug, "The Prevalence of Peripheral Arterial Disease in High Risk Subjects and Coronary or Cerebrovascular Patients," Angiology, Vol. 58, No. 3, 2007, pp. 309-315. http://dx.doi.org/10.1177/0003319707302494

[32] I. D. J. M. Moussa, R. Mehran, W. Gray, et al., "Prevalence and Prediction of Previously Unrecognized Peripheral Arterial Disease in Patients with Coronary Artery Disease: The Peripheral Arterial Disease in Interventional Patients Study," Catheterization and Cardiovascular Interventions, Vol. 73, No. 6, 2009, pp. 719-724. http://dx.doi.org/10.1002/ccd.21969

[33] S. T. Chang, C. L. Chen, C. M. Chu, P. C. Lin, C. M. Chung, J. T. Hsu, H. W. Cheng, T. Y. Yang and K. C. Hung, "Ankle-Arm Index Is a Useful Test for Clinical Practice in Outpatients with Suspected Coronary Artery Disease," Circulation Journal, Vol. 70, No. 6, 2006, pp. 686-690. http://dx.doi.org/10.1253/circj.70.686

[34] H. E. Resnick, R. S. Lindsay, M. M. McDermott, et al., "Relationship of High and Low Ankle Brachial Index to All-Cause and Cardiovascular Disease Mortality: The Strong Heart Study," Circulation, Vol. 109, No. 6, 2004, pp. 733-739.

http://dx.doi.org/10.1161/01.CIR.0000112642.63927.54 